\title{
ChemComm
}

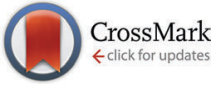

Cite this: Chem. Commun., 2015, 51, 3098

Received 10th October 2014 Accepted 5th January 2015

DOI: $10.1039 / c 4 c c 08027 \mathrm{k}$

www.rsc.org/chemcomm

\section{A simple modular aptasensor platform utilizing cucurbit[7]uril and a ferrocene derivative as an ultrastable supramolecular linker $\dagger$}

\author{
Don-Wook Lee, $\ddagger^{\mathrm{ab}}$ Kyeng Min Park, $\ddagger^{\mathrm{a}}$ Bokyoung Gong, ${ }^{\text {ac }}$ Dinesh Shetty, ${ }^{a}$ \\ Jayshree K. Khedkar, ${ }^{a}$ Kangkyun Baek, ${ }^{a}$ Jeehong Kim, ${ }^{\text {ac }}$ Sung Ho Ryu ${ }^{\star b d}$ and \\ Kimoon Kim*abce
}

\begin{abstract}
A simple modular aptamer-based sensor (aptasensor) platform was prepared by combining the merits of the rapid and efficient preparation of a self-assembled monolayer of cucurbit[7]uril (CB[7] SAM) and the strong and specific binding affinity of $\mathrm{CB}[7]$ to ferrocenemethylammonium (FA), as an ultrastable supramolecular linker, to immobilize aptamers on CB[7] SAM.
\end{abstract}

Aptamers are the artificial nucleotide sequences that fold into secondary and tertiary structures with high selectivity and specificity to target molecules including proteins, peptides and small organic molecules. ${ }^{1}$ Along with these features, aptamers have shown extraordinary promise in analytical applications due to their easy chemical synthesis and modifications with reporter molecules, linkers, and other functional groups. ${ }^{2}$ Many researchers have thus explored the aptamers as highly selective biorecognition components in bioassays and biosensing. ${ }^{2,3}$ Apart from the inherent advantages of biosensors, aptamer-based biosensors (aptasensors) offer the advantage of reusability utilizing reversible structural-switching. ${ }^{4}$ Furthermore, their small size and chemical functionalities allow efficient immobilization at high density, ${ }^{5}$ which is of vital importance in multiplexing miniaturized systems. In spite of these rapid advances, aptamerbased bioassays are still immature compared to antibody-based immunoassays, thus reflecting the limited availability of aptamer

\footnotetext{
${ }^{a}$ Center for Self-assembly and Complexity, Institute for Basic Science (IBS), Pohang, 790-784, Republic of Korea

${ }^{b}$ School of Interdisciplinary Bioscience and Bioengineering, Pohang University of Science and Technology, Pohang, 790-784, Republic of Korea.

E-mail:kkim@postech.ac.kr

${ }^{c}$ Department of Chemistry, Pohang University of Science and Technology, Pohang, 790-784, Republic of Korea

${ }^{d}$ Division of molecular and Life Science, Department of Life Science, Pohang University of Science and Technology, Pohang, 790-784, Republic of Korea ${ }^{e}$ Division of Advanced Materials Science, Pohang University of Science and Technology, Pohang, 790-784, Republic of Korea

$\dagger$ Electronic supplementary information (ESI) available: Experimental details of chemical synthesis, SPR measurements and filter binding assays. See DOI: $10.1039 / \mathrm{c} 4 \mathrm{cc} 08027 \mathrm{k}$

\$ These authors contributed equally to this work.
}

types and the relatively poor knowledge of surface-immobilization technologies for aptamers. ${ }^{6}$ In this regard, the multiple processing steps for immobilization of aptamers on surfaces is a major concern in the development of such systems. ${ }^{7}$ The streptavidin-biotin binding pair ${ }^{8}$ has extensively been used as an efficient linker system to immobilize aptamers on surfaces ${ }^{5 b, 9}$ because of their strong and specific noncovalent interactions (binding constant $\sim 10^{13} \mathrm{M}^{-1}$ ). The multiple processing steps include the pretreatment of additional chemical reagents, such as alkane thiols, functionalized dextrans, polyethyleneglycol thiols (PEG-SH) and also requires a chemical modification of proteins with delicate handling. ${ }^{7,10}$ Each step in this process claims to be a crucial parameter in the analytical performance of aptasensors. Such limitations therefore necessitate a new aptasensor platform that can simplify the processing steps using a chemically stable binding pair which could be convenient in terms of storage and handling.

Earlier, we and other researchers reported that cucurbit[7]uril ( $\mathrm{CB}[7])$, a member of the host family cucurbit $[n]$ uril $(\mathrm{CB}[n], n=5-8$, $10,14)^{11,12}$ with a hydrophobic cavity and two identical carbonylfringed portals, binds the ferrocenemethylammonium (FA) ion with an exceptionally high binding affinity with a binding constant of $\sim 10^{12} \mathrm{M}^{-1}$ in aqueous solution. ${ }^{13}$ This exceptionally strong binding affinity of $\mathrm{CB}[7]$ to FA led us to develop a synthetic system successfully employed, as an alternative artificial system to a streptavidin-biotin binding pair, in biological applications such as immobilization of biomolecules on a solid surface and membrane protein isolation. ${ }^{14}$ Recently, Li and others reported a method for the formation of a self-assembled monolayer of $\mathrm{CB}[7]$ on a gold surface by dipping a gold surface into a solution of $\mathrm{CB}[7] .^{15}$ It was observed that $\mathrm{CB}[7]$ molecules on the gold surface are uniform in their orientation and hold carbonyl portals perpendicular to the plane of the surface to maintain the guest binding and recognition properties of $\mathrm{CB}[7]$. Further, Brunsveld et al. demonstrated simple and reversible immobilization of FA-conjugated yellow fluorescent protein (FA-YFP) on $\mathrm{CB}[7] \cdot{ }^{16}$ Although aptamers have become increasingly important molecular tools in the biosensing field because of the inherent advantages mentioned above, the immobilization of aptamers on $\mathrm{CB}[7]$ has not been reported yet. 
Described herein is a simple modular aptasensor platform obtained by combining the merits of both simple preparation of $\mathrm{CB}$ [7] SAM and highly strong and selective binding affinity of $\mathrm{CB}$ [7] to FA. We utilize the $\mathrm{FA}-\mathrm{CB}[7]$ binding pair system as an ultrastable supramolecular linker, with the help of which various FA-conjugated aptamers can efficiently be immobilized on $\mathrm{CB}$ [7] SAM for surface plasmon resonance (SPR) studies (Scheme 1). Our present aptasensor system bears unique features including (1) easy preparation of $\mathrm{CB}[7] \mathrm{SAM}$ by either direct injection of $\mathrm{CB}[7]$ onto a gold surface or dipping a gold surface into a solution of $\mathrm{CB}[7]$, (2) versatility of $\mathrm{CB}$ [7] SAM for immobilization of various FA-conjugated aptamers, (3) resistance to harsh conditions such as elevated temperature or unwanted enzymatic degradation, and (4) long-term durability due to the usage of stable synthetic molecules, ${ }^{14 b}$ instead of (strept)avidin proteins used in conventional aptasensors. This FA-CB[7] linker-based aptasensor may act as a simple and efficient bio-sensor including proteins and thus widen the practical applications of aptasensors.

$\mathrm{CB}$ [7] SAM was prepared by simply dipping a gold surface into a solution of $\mathrm{CB}$ [7] $\left(1.0 \mathrm{mM}\right.$ in deionized $\left.\mathrm{H}_{2} \mathrm{O}\right)$ for $6 \mathrm{~h}$ as per the literature reports ${ }^{15 a}$ and conveniently kept at RT until it was ready to be used as a sensor chip. Direct injections of $\mathrm{CB}$ [7] solution (1.0 mM in deionized $\mathrm{H}_{2} \mathrm{O}, 20 \mathrm{~min}, 20 \mu \mathrm{L} \mathrm{min}{ }^{-1}$ ) onto a gold surface mounted in a SPR machine were also conducted as an alternative method. After 5 sequential injections, we observed approximately $500 \mathrm{RU}\left(1000 \mathrm{RU}=1 \mathrm{ng} \mathrm{\textrm {mm } ^ { - 2 }}\right)^{17}$ of sensor response (Fig. S1, ESI $\dagger$ ) which turned out to be $0.43 \mathrm{pmol}$ of $\mathrm{CB}[7]$ on $1 \mathrm{~mm}^{2}$. This result suggested that $c a$. 55\% of a plain gold surface is covered with $\mathrm{CB}[7]$ by considering the theoretical density of densely packed $\mathrm{CB}[7]$ (of diameter $1.6 \mathrm{~nm})^{12 b}$ on a plane surface $\left(0.75 \mathrm{pmol} \mathrm{mm}^{-2}\right)$. In AFM images (Fig. S2, ESI $\dagger$ ), small dots approximately $1 \mathrm{~nm}$ in height and only little aggregation appeared on a gold surface after treatment of $\mathrm{CB}[7]$. The SPR and AFM results suggest that even simple direct injections of $\mathrm{CB}[7]$ solution to a gold surface can lead to the formation of $\mathrm{CB}[7] \mathrm{SAM}$ on a gold sensor chip. Since $\mathrm{CB}[7]$ is a stable molecule synthesized under highly acidic conditions at high temperature, ${ }^{11 a, b}$ and it has higher
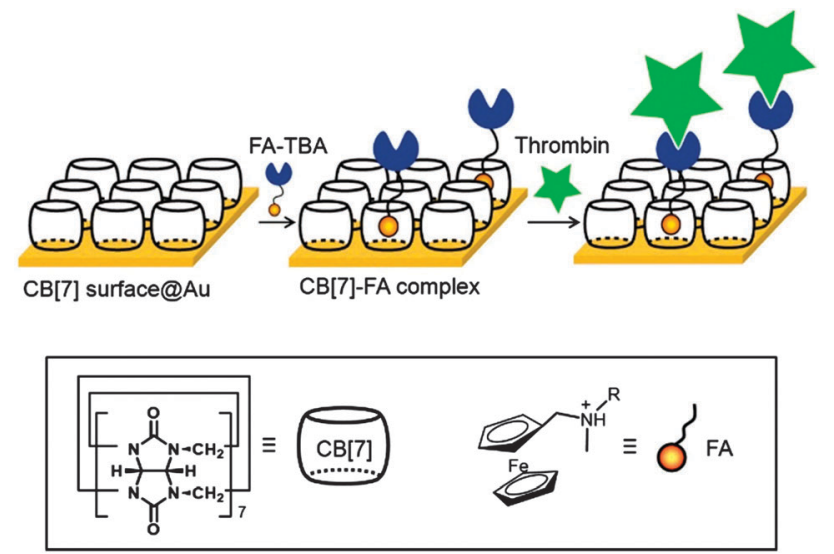

Scheme 1 Immobilization of the ferrocenemethylammonium-conjugated thrombin binding aptamer (FA-TBA) on a CB[7] SAM using the strong biding affinity of $\mathrm{CB}[7]$ to $\mathrm{FA}$, and its application as an aptasensor chip for sensing thrombin. resistance to harsh conditions and better long-term durability compared to (strept)avidin, which suggests that $\mathrm{CB}$ [7] SAM can be useful as a robust aptasensor platform.

In the present work, a carefully studied aptamer (TBA, 15-mer DNA-based) that binds strongly and selectively to thrombin was chosen as the model probe. ${ }^{18}$ By exploiting $\mathrm{FA}-\mathrm{CB}[7]$ interactions for the immobilization of TBA on $\mathrm{CB}$ [7] SAM, it was first "ferrocenylated"14a by conjugation of carboxylated FA $(\mathbf{1})^{14 b}$ to aminohexyl group at the $5^{\prime}$ terminus using EDC (1-ethyl-3-(3dimethylaminopropyl)carbodiimide) coupling (Scheme 2). Thus formed ferrocenylated TBA (FA-TBA) was further purified and characterized using HPLC and ESI-mass spectroscopy, respectively (Fig. S4, ESI $\dagger$ ). A binding constant of chemically modified TBA $\left(\sim 10^{9} \mathrm{M}^{-1}\right)$ measured via a filter binding assay ${ }^{19}$ was noted to be comparable to that of unmodified TBA. This implies that the ferrocenylation barely affects the binding affinity of TBA to its target protein, thrombin. ${ }^{20}$

After 25 min of injection of FA-TBA and TBA into each channel on the $\mathrm{CB}[7]$ sensor chip, $700 \mathrm{RU}$ and $30 \mathrm{RU}$, respectively, were observed at $1920 \mathrm{~s}$ (Fig. 1). The higher RU value ( $\sim 23$-fold) for FA-TBA compared to TBA proves its importance for effective immobilization of aptamers. The converted density of FA-TBA on $\mathrm{CB}$ [7] SAM from the RU value $\left(0.12 \mathrm{pmol} \mathrm{mm}^{-2}\right)$, suggested that approximately one out of four $\mathrm{CB}$ [7] molecules on average seemed to capture one FA-TBA. This result suggested successful immobilization of FA-TBA on $\mathrm{CB}$ [7] SAM by making the use of strong and specific interactions between $\mathrm{CB}[7]$ and FA. To check the versatility of $\mathrm{CB}$ [7] SAM for immobilization of various

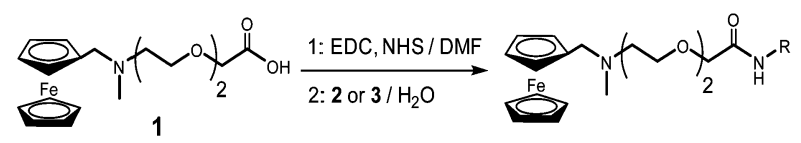

Amine terminated thrombin DNA aptamer: 5'- $\mathrm{NH}_{2} \mathrm{C}_{6} \mathrm{H}_{12}$-GGT TGG TGT GGT TGG-3' (2) Amine terminated scrambled DNA sequences: $5^{\prime}-\mathrm{NH}_{2} \mathrm{C}_{6} \mathrm{H}_{12}$-GGT GGT GGT TGT GGT-3' (3)

$\mathrm{R}=$ Thrombin DNA aptamer: $-\mathrm{C}_{6} \mathrm{H}_{12}$-GGT TGG TGT GGT TGG-3' (FA-TBA) Scrambled DNA sequences: - $\mathrm{C}_{6} \mathrm{H}_{12}$-GGT GGT GGT TGT GGT-3' (FA-SDNA)

Scheme 2 Conjugation of ferrocenemethylammonium to thrombin binding aptamer (FA-TBA) and scrambled DNA sequences (FA-SDNA).

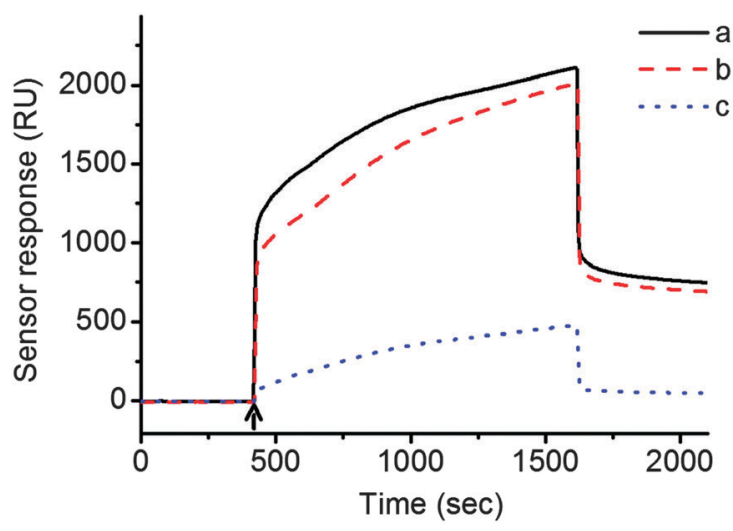

Fig. 1 SPR sensorgrams of CB[7] SAM treated with (a) FA-TBA, (b) FA-SDNA and (c) TBA (the arrow indicates injection of samples). 
aptamers, we prepared FA-scrambled DNA (FA-SDNA) with the same molecular weight as FA-TBA but with different DNA sequences (Scheme 2). The observed RU value i.e. 670, for FA-SDNA injection was almost in line with that of FA-TBA. This finding clearly shows that CB[7] SAM can not only immobilize FA-TBA but also other various aptamers as long as they are conjugated with FA utilizing the strong and specific interaction between $\mathrm{CB}[7]$ and FA as a supramolecular linker.

Having established FA-aptamer@CB[7] SAM as a simple and modular aptasensor system, we examined the feasibility of FA-TBA@CB[7] SAM as a model SPR sensor chip. To confirm the selective recognition of thrombin, we injected it and bovine serum albumin (BSA, as a negative control) into a different channel on the FA-TBA@CB[7] sensor chip. Accordingly, after 15 min of injection, we observed $340 \mathrm{RU}$ for thrombin and 35 RU for BSA (Fig. S5, ESI $\dagger$ ). These values signify the specific recognition and non-specific adsorption, respectively. Moreover, the higher sensor response of thrombin as compared to BSA, by one order of magnitude, denotes its selective recognition. Furthermore, a concentration dependent sensor response was observed by injection of different thrombin concentrations to a channel of the FA-TBA@CB[7] sensor chip (Fig. 2). These recorded responses ranged from the sub-ppm to the ppm level, thus showing the sensing of target protein in nanomolar concentrations. Even though this noted analytical performance of FA-TBA@CB[7] sensor chip is comparable to that of the streptavidin-biotin binding pair based system reported earlier, ${ }^{7}$ the former comes up with the benefits of effortless preparation, resistance to harsh conditions, long term durability and reusability by utilizing either reversible structural-switching of aptamers ${ }^{4}$ or reversible noncovalent binding properties of $\mathrm{CB}[7]$ to $\mathrm{FA}^{12 g, 21}$ as previously demonstrated for proteins. ${ }^{16}$

In summary, we have successfully demonstrated the efficient and versatile immobilization of FA-conjugated aptamers with FA-TBA and FA-SDNA on CB[7] SAM by taking advantage of its facile formation on a gold surface and also ultrastable binding

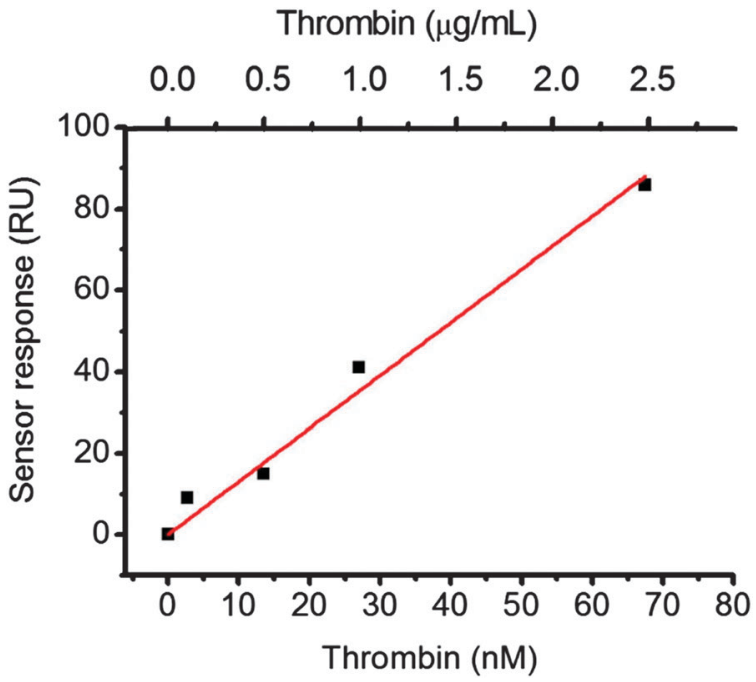

Fig. 2 Sensor responses as a function of the thrombin concentration on the CB[7] SAM SPR sensor chip (15 $\min , 5 \mu \mathrm{L} \min ^{-1}$ ). of $\mathrm{CB}[7]$ to FA. The profound analysis of a target protein using FA-TBA@CB[7] SAM proved the utility of the FA-CB[7] binding pair as an efficient linker system providing a new aptasensor platform. Furthermore, the optimization of the formation of $\mathrm{CB}$ [7] SAM and immobilization of FA-aptamers using functionalized $\mathrm{CB}[7],{ }^{22}$ which can further control the density of $\mathrm{CB}[7]$ on a gold surface, may result in the enhanced analytical performance of $\mathrm{CB}[7]$-based aptasensors.

This work was supported by the Institute for Basic Science (IBS) [IBS-R007-D1-2014-a00] and the National Research Foundation of Korea (NRF) grant funded by the Korea government (MEST) (No. 2013R1A2A1A03010110).

\section{Notes and references}

1 (a) A. B. Iliuk, L. $\mathrm{Hu}$ and W. A. Tao, Anal. Chem., 2011, 83, 4440-4452; (b) D. S. Wilson and J. W. Szostak, Annu. Rev. Biochem., 1999, 68, 611-647; (c) S. M. Shamah, J. M. Healy and S. T. Cload, Acc. Chem. Res., 2008, 41, 130-138.

2 E. Luzi, M. Minunni, S. Tombelli and M. Mascini, TrAC, Trends Anal. Chem., 2003, 22, 810-818.

3 (a) S. D. Jayasena, Clin. Chem., 1999, 45, 1628-1650; (b) W. Zhou, P. J. Huang, J. Ding and J. Liu, Analyst, 2014, 139, 2627-2640; (c) S. P. Song, L. H. Wang, J. Li, J. L. Zhao and C. H. Fan, TrAC, Trends Anal. Chem., 2008, 27, 108-117; (d) W. Mok and Y. F. Li, Sensors, 2008, 8, 7050-7084; (e) C. Tuerk and L. Gold, Science, 1990, 249, 505-510; $(f)$ S. Tombelli, M. Minunni and M. Mascini, Biomol. Eng., 2007, 24, 191-200; $(g)$ K. Sefah, J. A. Phillips, X. Xiong, L. Meng, D. Van Simaeys, H. Chen, J. Martin and W. Tan, Analyst, 2009, 134, 1765-1775; (h) S. Tombelli, M. Minunni and M. Mascini, Biosens. Bioelectron., 2005, 20, 2424-2434.

4 (a) Y. L. Zhang, Y. Huang, J. H. Jiang, G. L. Shen and R. Q. Yu, J. Am. Chem. Soc., 2007, 129, 15448-15449; (b) Z. S. Wu, M. M. Guo, S. B. Zhang, C. R. Chen, J. H. Jiang, G. L. Shen and R. Q. Yu, Anal. Chem., 2007, 79, 2933-2939.

5 (a) J. F. Lee, G. M. Stovall and A. D. Ellington, Curr. Opin. Chem. Biol., 2006, 10, 282-289; (b) M. Liss, B. Petersen, H. Wolf and E. Prohaska, Anal. Chem., 2002, 74, 4488-4495.

6 A. Bini, M. Minunni, S. Tombelli, S. Centi and M. Mascini, Anal. Chem., 2007, 79, 3016-3019.

7 V. Ostatna, H. Vaisocherova, J. Homola and T. Hianik, Anal. Bioanal. Chem., 2008, 391, 1861-1869.

8 (a) P. C. Weber, D. H. Ohlendorf, J. J. Wendoloski and F. R. Salemme, Science, 1989, 243, 85-88; (b) N. M. Green, Methods Enzymol., 1990, 184, 51-67; (c) C. E. Chivers, A. L. Koner, E. D. Lowe and M. Howarth, Biochem. J., 2011, 435, 55-63.

9 (a) A. Tahiri-Alaoui, L. Frigotto, N. Manville, J. Ibrahim, P. Romby and W. James, Nucleic Acids Res., 2002, 30, e45; (b) R. Kirby, E. J. Cho, B. Gehrke, T. Bayer, Y. S. Park, D. P. Neikirk, J. T. McDevitt and A. D. Ellington, Anal. Chem., 2004, 76, 4066-4075.

10 (a) D. T. Tran, K. Knez, K. P. Janssen, J. Pollet, D. Spasic and J. Lammertyn, Biosens. Bioelectron., 2013, 43, 245-251; (b) J. Ashley and S. F. Y. Li, Biosens. Bioelectron., 2013, 48, 126-131; (c) J. W. Lee, S. J. Sim, S. M. Cho and J. Lee, Biosens. Bioelectron., 2005, 20, 1422-1427.

11 (a) J. Kim, I. S. Jung, S. Y. Kim, E. Lee, J. K. Kang, S. Sakamoto, K. Yamaguchi and K. Kim, J. Am. Chem. Soc., 2000, 122, 540-541; (b) A. Day, A. P. Arnold, R. J. Blanch and B. Snushall, J. Org. Chem., 2001, 66, 8094-8100; (c) S. Liu, P. Y. Zavalij and L. Isaacs, J. Am. Chem. Soc., 2005, 127, 16798-16799; (d) X. J. Cheng, L. L. Liang, K. Chen, N. N. Ji, X. Xiao, J. X. Zhang, Y. Q. Zhang, S. F. Xue, Q. J. Zhu, X. L. Ni and Z. Tao, Angew. Chem., Int. Ed., 2013, 52, 7252-7255.

12 (a) K. Kim, Chem. Soc. Rev., 2002, 31, 96-107; (b) J. W. Lee, S. Samal, N. Selvapalam, H. J. Kim and K. Kim, Acc. Chem. Res., 2003, 36, 621-630; (c) E. Masson, X. X. Ling, R. Joseph, L. Kyeremeh-Mensah and X. Y. Lu, RSC Adv., 2012, 2, 1213-1247; (d) S. Gadde and A. E. Kaifer, Curr. Org. Chem., 2011, 15, 27-38; (e) L. Isaacs, Chem. Commun., 2009, 619-629; $(f)$ J. Lagona, P. Mukhopadhyay, S. Chakrabarti and L. Isaacs, Angew. Chem., Int. Ed., 2005, 44, 4844-4870; (g) A. E. Kaifer, Acc. Chem. Res., 2014, 47, 2160-2167. 
13 (a) W. S. Jeon, K. Moon, S. H. Park, H. Chun, Y. H. Ko, J. Y. Lee, E. S. Lee, S. Samal, N. Selvapalam, M. V. Rekharsky, V. Sindelar, D. Sobransingh, Y. Inoue, A. E. Kaifer and K. Kim, J. Am. Chem. Soc., 2005, 127, 12984-12989; (b) M. V. Rekharsky, T. Mori, C. Yang, Y. H. Ko, N. Selvapalam, H. Kim, D. Sobransingh, A. E. Kaifer, S. Liu, L. Isaacs, W. Chen, S. Moghaddam, M. K. Gilson, K. Kim and Y. Inoue, Proc. Natl. Acad. Sci. U. S. A., 2007, 104, 20737-20742; (c) S. Liu, C. Ruspic, P. Mukhopadhyay, S. Chakrabarti, P. Y. Zavalij and L. Isaacs, J. Am. Chem. Soc., 2005, 127, 15959-15967.

14 (a) I. Hwang, K. Baek, M. Jung, Y. Kim, K. M. Park, D. W. Lee, N. Selvapalam and K. Kim, J. Am. Chem. Soc., 2007, 129, 4170-4171; (b) D. W. Lee, K. M. Park, M. Banerjee, S. H. Ha, T. Lee, K. Suh, S. Paul, H. Jung, J. Kim, N. Selvapalam, S. H. Ryu and K. Kim, Nat. Chem., 2011, 3, 154-159.

15 (a) Q. An, G. T. Li, C. G. Tao, Y. Li, Y. G. Wu and W. X. Zhang, Chem. Commun., 2008, 1989-1991; (b) E. Blanco, C. Quintana, L. Hernandez and P. Hernandez, Electroanalysis, 2013, 25, 263-268; (c) A. GomezCasado, P. Jonkheijm and J. Huskens, Langmuir, 2011, 27, 11508-11513.
16 J. F. Young, H. D. Nguyen, L. Yang, J. Huskens, P. Jonkheijm and L. Brunsveld, ChemBioChem, 2010, 11, 180-183.

17 X. Q. Cui, R. J. Pei, X. Z. Wang, F. Yang, Y. Ma, S. J. Dong and X. R. Yang, Biosens. Bioelectron., 2003, 18, 59-67.

18 (a) L. C. Bock, L. C. Griffin, J. A. Latham, E. H. Vermaas and J. J. Toole, Nature, 1992, 355, 564-566; (b) R. F. Macaya, P. Schultze, F. W. Smith, J. A. Roe and J. Feigon, Proc. Natl. Acad. Sci. U. S. A., 1993, 90, 3745-3749.

19 R. Conrad and A. D. Ellington, Anal. Biochem., 1996, 242, 261-265.

20 E. Baldrich, A. Restrepo and C. K. O'Sullivan, Anal. Chem., 2004, 76, 7053-7063.

21 (a) D. Sobransingh and A. E. Kaifer, Org. Lett., 2006, 8, 3247-3250; (b) W. Li and A. E. Kaifer, Langmuir, 2012, 28, 15075-15079.

22 (a) S. Y. Jon, N. Selvapalam, D. H. Oh, J. K. Kang, S. Y. Kim, Y. J. Jeon, J. W. Lee and K. Kim, J. Am. Chem. Soc., 2003, 125, 10186-10187; (b) K. Kim, N. Selvapalam, Y. H. Ko, K. M. Park, D. Kim and J. Kim, Chem. Soc. Rev., 2007, 36, 267-279. 